\title{
EPIDEMIOLOGY OF HYPONATRAEMIA AMONG ELDERLY PATIENTS WITH LOWER RESPIRATORY TRACT INFECTION
}

\author{
B. RAJU ${ }^{1}$, A RISHAB ${ }^{2}, \mathrm{~K} V I K R A M^{3}$, T. VAIBHAV ${ }^{3}$, T SHARAT ${ }^{3}, \mathrm{G} \mathrm{KOPAL}^{3}, \mathrm{~K} \mathrm{SANTOSH}^{3}, \mathrm{~A} \mathrm{SHREYAS}^{3}$
}

\begin{abstract}
Background: Decrease in serum sodium concentration is frequent observation among hospitalised elderly patients. The common causes for hyponatremia are degenerative physiology, dehydration, medications and infections. Hence the present study was undertaken to know the extent of hyponatremia among elderly with Lower Respiratory Tract Infections.
\end{abstract}

Objectives: The present study was undertaken to assess the prevalence of hyponatremia in lower respiratory tract infection among geriatric age group and to determine the association between severity of hyponatraemia and LRTI.

Methods: This was hospital based cross sectional study carried out in the Department of General Medicine of a tertiary care teaching hospital situated in north Karnataka, India during November 2016 to May 2018. 100 elderly patients (age e" 60 years) with history of cough for more than four to five days, clinical findings and X-ray findings suggestive of LRTI, were selected for the study.

Results: In the present study 59\% comprised of male whereas females constituted $41 \%$. The prevalence of hyponatraemia among elderly patients with LRTI was 45\%. The most common cause of hyponatraemia was GI loss (vomiting) 53.33\%, Euvolemic hyponatramia $51.11 \%$. The mean age was 69.99 \pm 8.44 years. Most of the patients were aged between 61 to 70 years. Hyponatraemia was not associated with sex, age and type of LRTI. Duration of hospital stay was significantly longer in patients with hyponatraemia compared to those who did not develop hyponatraemia.

Conclusion: Hyponatraemia among elderly individuals with LRTI is higher as compared to other age group hence leading to prolonged duration of hospitalisation.

Keywords: Hyponatraemia, Elderly, Lower Respiratory Tract Infection (LRTI), Lobar Pnemonia.

Received: 14 June 2019

Accepted: 18 December 2019

DOI: https://doi.org/10.3329/bjmed.v31i1.44748

\section{Introduction}

Acute lower respiratory tract infections (LRTI) such as pneumonia and acute bronchitis are among the most common reasons to visit a general practitioner, notably among elderly persons. ${ }^{1}$ Elderly person are more likely to develop complications from LRTI compared with younger patients as they have a greater burden of underlying diseases and a different response to therapy. ${ }^{2}$

Hyponatremia is the common electrolyte imbalance encountered in clinical practice. ${ }^{3}$ It occurs due to disruption of sodium and water homeostasis, normally maintained by complex multi-system physiological mechanisms. ${ }^{4}$ It represents an excess of water relative to sodium, though both sodium and total body water may be increased, normal or diminished. Consequently, there are numerous potential underlying causes of hyponatremia, spanning a broad spectrum of diseases. ${ }^{5}$

Hyponatremia is common among older people. Prevalence of hyponatremia is known to increase in frail patient groups, particularly elderly patients where hyponatremia is observed in almost half of acute geriatric admissions. ${ }^{6,7}$ Older people have an increased predisposition to hyponatremia due to degenerate physiology, multiple co-morbidities and polypharmacy. ${ }^{4}$ Hospitalized older people have a further susceptibility to hyponatremia due to dehydration, inappropriate fluid therapy and iatrogenic interventions. In an Indian study, with only elderly

1. AP, Department of Medicine, JN Medical College, Belagavi.

2. $\quad$ PG and corresponding Author, Department of Medicine, JN Medical College, Belagavi

3. PG, Department of Medicine, JN Medical College, Belagavi.

Address of Correspondence: Dr. B. Raju, AP, Department of Medicine, JN Medical College, Belagavi. 
hospitalized patients, the most common causes of hyponatremia were Syndrome of Inappropriate Anti diuretic Hormone secretion (SIADH) and diuretics. The two most common causes of SIADH were lower respiratory tract infection and stroke. ${ }^{8}$ However despite of hyponatraemia in elderly patients with LRTI being an important predictor of morbidity and mortality, to our knowledge none of the study is reported on prevalence of hyponatraemia in elderly patients with LRTI so far. Hence the present study was undertaken to assess the prevalence of hyponatremia in lower respiratory tract infection among geriatric age group and to determine the association between severity of hyponatraemia and LRTI.

\section{Methodology}

This hospital based cross sectional study was undertaken in the Department of General Medicine of a tertiary care teaching hospital situated in north Karnataka, India from November 2016 to May 2018. Considering the availability of cases, feasibility, and available time period a total of 100 elderly patients (age e" 60 years) who presented with history of cough for more than four to five days, clinical findings and $\mathrm{X}$-ray findings suggestive of LRTI, were selected for the study. Patients with upper respiratory tract infection, known cardiac disease, diabetes mellitus, hypertension, renal diseases and terminally ill patients were excluded from the study. The ethical clearance was obtained from the Institutional Ethical committee, Jawaharlal Nehru Medical College, Belgaum prior to the commencement.

Patients who were eligible were briefed about the nature of the study and a written informed consent was obtained. Patients were interviewed and demographic data like gender and age were noted. A thorough general physical examination was conducted to assess vital parameters, anthropometry and clinical signs followed by systemic examination. All these findings were recorded on a predesigned and pretested proforma. Further, Blood sample was collected for laboratory investigations. Blood samples were collected under all aseptic precautions; blood samples were collected by venepuncture and collected in vacutainer.the sample was collected within 6hours of admission and send for further analysis to department of biochemistry and department of pathology. Patients with lower respiratory tract infections were evaluated for hyponatremia and graded according to severity of pneumonia. All cases were provided treatment according to the diagnosis and routine hospital protocols. All cases were followed up till the hospital stay to assess outcomes, mortality, morbidity and complications. Severity of hyponatremia was defined as Mild (serum sodium concentration 131-135mmol/ L), Moderate (serum sodium concentration 126-130 $\mathrm{mmol} / \mathrm{L}$ ) and Severe (serum sodium concentration less than $125 \mathrm{mmol} / \mathrm{L})$.

\section{Outcome variables}

Patients were evaluated for the presence and Severity of hyponatremia. The association between hyponatremiawith demographic determinants that is age and sex, type of LRTI was determined. Also length of hospital stay was determined.

\section{Statistical analysis}

The data obtained was tabulated on Microsoft Excel spreadsheet. The categorical data was expressed as ratios and percentages. The prevalence of hyponatremia among elderly patients with LRTI was expressed in terms of percentage. Chi-square test and/ or Fisher's exact test was used to find the association between the hyponatraemia and age as well as sex. The comparison of mean hospital stay among those with and without hyponatremia was expressed as mean \pm standard deviation (SD) and independent sample ' $t$ ' test was used to compare the data. At 95\% confidence interval (CI), a probability value ('p' value) of less than or equal to 0.050 was considered to be statistically significant.

\section{Results}

In the present study 45 out of 100 patients developed hyponatraemia hence, the prevalence of hyponatraemia among elderly patients with LRTI was $45 \%$ (Graph 1). Among the patients with hyponatraemia, the mean serum sodium levels were $129.96 \pm 4.32 \mathrm{mmol} / \mathrm{L}$ and the median serum sodium levels were $131 \mathrm{mmol} / \mathrm{L}$ and ranged between 118 to $134 \mathrm{mmol} / \mathrm{L}$.

With regard to severity, mild hyponatraemia was noted in $31 \%$ of the patients, moderate in $10 \%$ and severe hyponatraemia was present among $4 \%$ of the patients (Graph 2). The most common cause of hyponatraemia was GI loss (vomiting) which was noted in 24 patients (53.33\%) out of 45 patients with hyponatraemia (Graph 3). The Euvolemic hyponatramia was common type noted in 23 of 45 patients (51.11\%) (Graph 4).

Out of 100,59 patients were males (59\%) and 41 were females (41\%) (Table 1). The age ranged between 60 to 89 years and the mean age was $69.99 \pm 8.44$ years. Most of the patients were aged between 61 to 70 years (Table $2)$. With respect to type of LRTI, $47 \%$ of the patients had Lobar pneumonia, $45 \%$ of the patients had bronchopneumonia while bronchitis and Empyema were diagnosed in $6 \%$ and $2 \%$ of the Patients respectively (Table 3). Hyponatraemia was not 
Table-I

Various socio-demographic and clinical factors associated with hyponatraemia

\begin{tabular}{|c|c|c|c|c|c|c|c|}
\hline \multirow[t]{3}{*}{$\overline{\operatorname{Sex}}$} & \multicolumn{6}{|c|}{ Hyponatraemia } & \multirow{3}{*}{$\mathrm{P}$ value } \\
\hline & \multicolumn{2}{|c|}{ Present } & \multicolumn{2}{|c|}{ Absent } & \multicolumn{2}{|c|}{ Total } & \\
\hline & No & $\%$ & No & $\%$ & No & $\%$ & \\
\hline Male & 33 & 55.93 & 26 & 44.07 & 59 & 59.00 & 0.841 \\
\hline Female & 22 & 53.66 & 19 & 46.34 & 41 & 41.00 & \\
\hline Total & 55 & 55.00 & 45 & 45.00 & 100 & 100.00 & \\
\hline \multicolumn{8}{|l|}{ Age Group } \\
\hline 61 to 70 & 25 & 57.63 & 34 & 57.63 & 59 & 59.00 & 0.438 \\
\hline 71 to 80 & 12 & 57.14 & 16 & 57.14 & 28 & 28.00 & \\
\hline 81 to 90 & 8 & 38.46 & 5 & 38.46 & 13 & 13.00 & \\
\hline Total & 55 & 55.00 & 55 & 55.00 & 100 & 100.00 & \\
\hline \multicolumn{8}{|l|}{ Type of LRTI } \\
\hline Bronchitis & 4 & 33.33 & 2 & 33.33 & 6 & 6.00 & 0.729 \\
\hline Bronchopneumonia & 19 & 57.78 & 26 & 57.78 & 45 & 45.00 & \\
\hline Empyema & 1 & 50.00 & 1 & 50.00 & 2 & 2.00 & \\
\hline Lobar pneumonia & 21 & 55.32 & 26 & 55.32 & 47 & 47.00 & \\
\hline Total & 55 & 55.00 & 55 & 55.00 & 100 & 100.00 & \\
\hline
\end{tabular}

associated with sex $(\mathrm{p}=0.841)$, age $(\mathrm{p}=0.438)$ and type of LRTI ( $\mathrm{p}=0.729)$ (Table 1, 2 and 3).

No statistically significant difference was noted with regard to the mean age in patients with and without hyponatraemia $(71.53 \pm 8.70$ years vs $68.72 \pm 8.08$ years; $\mathrm{p}=0.101$ ) but duration of hospital stay was significantly longer in patients with hyponatraemia compared to those who did not develop hyponatraemia (10.26 \pm 4.63 days vs $5.81 \pm 2.78$ days; $\mathrm{p}<0.001)$.

\section{Discussion}

The primary findings from this single centre prospective study emphasizes high incidence of hyponatraemia among geriatric patients admitted with LRTI. In this study 45 out of 100 geriatric patients admitted with LRTI developed hyponatraemia which suggests that, almost one out of every three geriatric patients admitted with LRTI is at risk of developing one or the other form hyponatraemia. Most of the patients in this study developed mild hyponatraemia and euvolemic hyponatraemia was common type while GI loss was the common cause of developing hyponatraemia. Furthermore, the presence of hyponatramia is likely to prolong length of hospital stay. The data on hyponatramia among elderly population admitted with LRTI is scant. ${ }^{8,9}$ The available literature suggests that, prevalence of chronic hyponatremia in the elderly population between $7 \%$ to $20 \%$ and to a large extent it depends on the level of serum sodium and the setting in which the measurement is made. When studying the risk factors for orthostatic hypotension in an otherwise healthy population, Caird et al. ${ }^{10}$ noted that approximately $7 \%$ of patients $>65$ years of age had serum sodium concentrations d" $137 \mathrm{mEq} / \mathrm{L}$. In contrast, with a serum sodium concentration, 135 $\mathrm{mEq} / \mathrm{L}$ used as a cutoff, the prevalence of chronic hyponatremia was approximately $20 \%$ among residents of a long term care facility. ${ }^{11}$ A similar prevalence was noted in a Veterans Affairs nursing home, whereas the prevalence was $8 \%$ in ambulatory patients. ${ }^{12}$ The most recent study designed to determine the prevalence of hyponatremia was limited to patients with severe decrements in serum sodium concentration to, $125 \mathrm{mEq} / \mathrm{L}$. Of 1400 elderly (e"65 years) patients admitted to an Israeli hospital, 6.2\% had such a disorder. ${ }^{13}$ The increasing prevalence of hyponatremia with age is best illustrated in an analysis of $>300,000$ samples obtained from $>120,000$ patients of various ages. ${ }^{14}$ With a serum sodium concentration, $136 \mathrm{mEq} / \mathrm{L}$ used as a cutoff and a \#30-year-old cohort as a reference group, patients.

The prevalence noted in the present study was comparable to the observations from a hospital based descriptive study by Rao MY et al. ${ }^{8}$ during 2010, who 
reported that of the total of 1440 elderly patients admitted to the medical ICU during the 18 month period, 518 patients (36\%) had serum Sodium $<135$ $\mathrm{mmol} / \mathrm{L}$ and 100 patients (6.9\%) had serum Sodium d" $125 \mathrm{mmol} / \mathrm{L}$. The mean age of patients with hyponatremia was 72 years with a range of 60 to 99 yrs.

Many studies in the past indicate a higher mortality in the elderly patients with severe hyponatremia, with mortality ranging from $33 \%$ to $86 \% .{ }^{16}$ However, in the present study no mortality was noted. Sterns ${ }^{15}$ reported a mortality rate of $5 \%$ when the serum sodium levels was $<105 \mathrm{mmol} / \mathrm{L}$.

According to Berl T. et al. ${ }^{9}$ (2013), more than 60 years had a significantly higher prevalence of hyponatremia both at presentation and as a hospital-acquired disorder. In summary, it is evident from multiple epidemiologic studies that the elderly are especially prone to the development of hyponatremia which was true in the present study also despite of LRTI being the predominant primary etiology at presentation.

In the present study prevalence of hyponatraemia was slightly high among males (55.93\%) compared to female $(53.66 \%)$ but the difference was statistically not significant $(p=0.841)$. on the contrary, in a study by Rao MR et al. ${ }^{8}$ (2010), Hyponatremia was more common in females and they seemed to better tolerate it than their male counterparts.

Chronic hyponatremia is frequently multifactorial in the elderly. ${ }^{9}$ In an observational study, similar to the present study, more than half of the patients with hyponatremia had more than one cause for the condition. The single most common cause of hyponatremia was SIADH and Thiazide diuretic use was a common contributing factor. But in the present study GI loss was the predominant cause. Heart failure is also a common comorbid condition in this age group which was noted among $11.11 \%$ of the patients in this study. Some studies have documented no underlying cause for the development of hyponatraemia among the elderly among in $>50 \%$ of cases. ${ }^{13,16}$

Overall the findings of the present study emphasize higher prevalence of hyponatraemia in elderly admitted with LRTI among selected patients after excluding known cardiac disease, diabetes mellitus, hypertension, renal diseases and terminally ill patients. The prevalence of hyponatraemia was independent of sex and type of LRTI. However these findings require further validation due to potential limitation of this study.

\section{References}

1. Bont J, Hak E, Hoes AW, Schipper M, Schellevis FG, Verheij TJ. A prediction rule for elderly rimary-care patients with lower respiratory tract infections. Eur Respir J. 2007;29(5):969-75. https:/ / doi.org/10.1183/ 09031936.00129706.PMid:17215313

2. van de Nadort C, Smeets HM, Bont J, Zuithoff NP, Hak E, Verheij TJ. Prognosis of primary care patients aged 80 years and older with lower respiratory tract infection. Br J Gen Pract 009;59(561):e110-5. https://doi.org/ 10.3399/bjgp09X420239 PMid:19341546 PMCid:PMC 2662122

3. Sherlock M, Thompson CJ. The syndrome of inappropriate antidiuretic hormone: Current and future management options. Eur J Endocrin 2010;162:13-8. https://doi.org/10.1530/EJE-09-1057 PMid:20164215

4. Soiza RL, Hoyle GE, Chua MPW. Electrolyte and salt disturbances in older people: Causes, management and implications. Rev Clin Gerontol 2008;18:143-58. https://doi.org/10.1017/S0959259809002822

5. Soiza RL, Cumming K, Clarke JM, Wood KM, Myint PK. Hyponatremia: Special Considerations in Older Patients. J Clin Med 2014;3(3):944-58. https:/ / doi.org/ 10.3390/jcm3030944 PMid:26237487 PMCid:PMC 4449639

6. Mannesse CK, Vondeling AM, van Marum RJ, van Solinge WW, Egberts TC, Jansen PA. Prevalence of hyponatremia on geriatric wards compared to other settings over four decades: A systematic review. Ageing Res Rev 2013;12:165-73. https://doi.org/10.1016/ j.arr.2012.04.006. PMid:22588025

7. Hoyle GE, Chua M, Soiza RL. Prevalence of hyponatremia in elderly patients. J Am Geriatr Soc 2006;54:1473. https://doi.org/10.1111/j.15325415.2006.00872.x PMid:16970667

8. Rao MY, Sudhir U, Anil Kumar T, Saravanan S, Mahesh E, Punith K. Hospital based descriptive study of symptomatic hyponatremia in elderly patients. J Assoc Physicians India 2010;58:667-9.

9. Berl T. An elderly patient with chronic hyponatremia. Clin J Am Soc Nephrol 2013; 8(3):469-75. https:// doi.org/10.2215/CJN.03100312 PMid:23037983

10. Caird FI, Andrews GR, Kennedy RD: Effect of posture on blood pressure in the elderly. Br Heart $\mathrm{J}$ 1973;35:527-30. https://doi.org/10.1136/ hrt.35.5.527 PMid:4716013 PMCid:PMC458649

11. Kleinfeld M, Casimir M, Borra S. Hyponatremia as observed in a chronic disease facility. J Am Geriatr Soc 1979;27:156-61. https://doi.org/10.1111/j.15325415.1979.tb06439.x PMid:429736 
12. Miller M, Morley JE, Rubenstein LZ. Hyponatremia in a nursing home population. J Am Geriatr Soc 1995;43: 1410-3. https://doi.org/10.1111/j.1532-5415.1995. tb06623.x PMid:7490395

13. Shapiro DS, Sonnenblick M, Galperin I, Melkonyan L, Munter G. Severe hyponatraemia in elderly hospitalized patients: Prevalence, aetiology and outcome. Intern Med J 2010;40:574-80. https://doi.org/10.1111/j.14455994.2010.02217.x PMid:20298512

14. Hawkins RC. Age and gender asrisk factors for hyponatremia and hypernatremia. Clin Chim Acta
2003;337:169-72. https://doi.org/10.1016/ j.ccen.2003.08.001 PMid:14568195

15. Sterns RH. Severe symptomatic hyponatremia: treatment and outcome. A study of 64 cases. Ann Intern Med 1987;107:656-64. https://doi.org/10.7326/00034819-107-5-656 PMid:3662278

16. Hirshberg B, Ben-Yehuda A. The syndrome of inappropriate antidiuretic hormone secretion in the elderly. Am J Med 1997;103:270-3. https://doi.org/ 10.1016/S0002-9343(97)00250-7. 